\title{
Revalorización de quito-oligosacáridos obtenidos a partir de subproductos de la industria pesquera como antimicrobianos naturales
}

\author{
Revalorisation of chito-oligosaccharides obtained from fishery \\ by-products as natural antimicrobials
}

Fecha de recepción y aceptación: 13 de abril de 2021 y 14 de mayo de 2021

DOI: $10.46583 /$ nereis_2021.13.855

\author{
L. Estruch-Ibáñez ${ }^{1}$ M. Sanz-Puig ${ }^{2}$; F. Lorenzo² $;$ R. Bertó ${ }^{2}$ y J. Torres ${ }^{1 *}$ \\ ${ }^{1}$ Instituto de Investigación en Medio Ambiente y Ciencia Marina (IMEDMAR). Universidad Católica de Valencia San Vicente Mártir. \\ ${ }^{*}$ Correspondencia: Universidad Católica de Valencia San Vicente Mártir. Instituto de Investigación en Medio Ambiente y Ciencia \\ Marina (IMEDMAR). Calle Guillem de Castro, 94. 46003 Valencia. España.E-mail: javier.torres@ucv.es \\ ${ }^{2}$ Departamento I+D+i. BETELGEUX-CHRISTEYNS.
}



Universidad Católica de Valencia

San Vicente Mártir

\section{RESUMEN}

La quitina es el polímero más común en la Tierra después de la celulosa y se encuentra principalmente en los caparazones de los crustáceos, entre otros. A partir de la quitina se puede obtener como derivado desacetilado el quitosano, con propiedades específicas como su capacidad biocida, que le ha proporcionado múltiples aplicaciones potenciales. No obstante, debido a su baja solubilidad, estas aplicaciones están limitadas y cobran especial importancia los quito-oligosacáridos (COS), productos obtenidos a partir del quitosano. Por ello y ante el aumento significativo de los subproductos de la industria pesquera en los últimos años, el objetivo del presente trabajo fue evaluar la capacidad biocida de diferentes formulaciones desarrolladas a partir de COS extraídos de subproductos de la industria pesquera frente a los principales microorganismos alimentarios, para su revalorización como antimicrobianos naturales. Con dicho fin, se evaluó la capacidad biocida de siete formulaciones siguiendo la norma UNE-EN 1276, frente a distintas especies de hongos y bacterias, mediante el recuento en placa. Los resultados obtenidos mostraron que todos los formulados presentaron capacidad biocida frente a los microorganismos estudiados y, en base a ellos, se pudo concluir que el formulado basado en COS3 es el candidato que mayor proyección presenta para el desarrollo de un futuro producto biocida sostenible.

PALABRAS CLAVE: quitina, quitosano, capacidad biocida.

\section{ABSTRACT}

Chitin is the most common polymer on Earth after cellulose and it is found mainly in the shells of crustaceans, among others. Chitosan can be obtained from chitin, it is a deacetylated derivative with specific properties such as biocide capacity, which has provided it with many potential applications. However, due to its low solubility these applications are limited and chito-oligosaccharides (COS), products obtained from chitosan, take on special interest. For this reason and before the significant increase in by-products of the fishing industry in recent years, the 
objective of this project was to evaluate the biocide capacity of different formulations developed from COS extracted from by-products of the fishing industry against the main food microorganisms, for their revaluation as natural antimicrobials. For that purpose, the biocide capacity of seven formulations was evaluated by plate count following the UNE-EN 1276 standard, against different species of fungi and bacteria. The results obtained showed that all the formulations presented biocide capacity against the studied microorganisms and, based on them, it was possible to conclude that the formula based on $\operatorname{COS} 3$ is the candidate with the greatest projection for the development of a future sustainable biocide product.

KEYWORDS: chitin, chitosan, biocide capacity.

\section{INTRODUCCIÓN}

El agotamiento de los recursos no renovables, el cambio climático y la pérdida de biodiversidad son algunas de las consecuencias que actualmente estamos sufriendo por haber seguido un modelo económico lineal, que consistía en fabricar, utilizar y desechar [1,2].

Ante esta problemática, la Unión Europea apuesta por implantar un modelo de economía circular, el cual consiste en aprovechar al máximo los recursos que se utilizan para que permanezcan el mayor tiempo posible en el ciclo de producción, reduciendo la generación de residuos y respetando en todo momento el medio ambiente, siguiendo una tendencia competente y verde [3]. Además, debido al crecimiento exponencial de la población, industrias como la alimentaria se ven forzadas a dar una respuesta rápida a su demanda y en consecuencia a aumentar la producción [4] y con ello los desechos de alimentos. Tanto es así que un estudio realizado por la Unión Europea entre 2007-2013 demostró que efectivamente se desperdiciaban 88 millones de toneladas de alimentos al año. No obstante, estos desperdicios pueden ser un recurso de alto valor añadido, pues pueden contener compuestos con propiedades antioxidantes, anticancerígenas o antimicrobianas. La quitina, por ejemplo, es un subproducto de la industria pesquera que posee un amplio espectro de aplicaciones en muchos campos. Aproximadamente la industria pesquera genera $10^{6}$ toneladas de quitina como flujo de desechos cada año y por ello es importante considerar la revalorización de este subproducto, ya que conduciría a la sostenibilidad ambiental, siguiendo el modelo de economía circular que la UE desea implantar $[5,6]$.

\section{Quitina}

La quitina se extrae principalmente de crustáceos, en particular de los exoesqueletos de camarones, cangrejos y langostas. No obstante, en la naturaleza también está presente, dando forma y determinando la rigidez en las paredes celulares de hongos y diatomeas, en algas verdes, corales, levaduras, en las cutículas de los insectos y en los endoesqueletos de los moluscos [7]. Es el segundo biopolímero más abundante en la naturaleza después de la celulosa, dado que se estima que se producen anualmente de $10^{10} \mathrm{a} 10^{12}$ toneladas de quitina en la Tierra. Por consiguiente, este polímero representa una fuente barata y fácilmente disponible [8-10]. Es un polisacárido natural biodegradable, no tóxico, biocompatible, hidratante y antimicrobiano que muestra interesantes propiedades fisiológicas, 
biológicas y farmacológicas [11, 12]. Por ello, se han encontrado aplicaciones en la industria alimentaria, agraria, farmacéutica, cosmética, textil e incluso en la electrónica para la producción de biosensores; un ejemplo de ello es su utilidad para controlar la liberación de fármacos teniendo en cuenta su biodegradabilidad, baja toxicidad, carácter hidrófilo, propiedad antibacteriana, de formación de gel, afinidad por proteínas y mucoadhesividad. Asimismo, también se utiliza como conservante de alimentos debido a sus propiedades antimicrobianas, como cosmético en el cuidado de la piel, cabello y cuidado bucal, en la curación de heridas y en tratamientos de aguas residuales [13, 14]. No obstante, el uso de la quitina está significativamente limitado debido a que es insoluble en agua, soluciones ácidas, alcalinas y en solventes orgánicos. Además, es una molécula difícil de manipular y procesar, por lo que su escasa solubilidad junto con su difícil manipulación hace que su uso esté limitado en muchas aplicaciones y por ello cobra interés su derivado desacetilado, el quitosano $[8,15]$.

\section{Quitosano}

El quitosano es un polímero lineal de la familia de las poliaminoglucosas que se obtiene por la desacetilación parcial de la quitina en condiciones alcalinas, de modo que se considera quitosano siempre y cuando el número de unidades desacetiladas sean mayor o igual al $50 \%$ de las unidades totales. Por el contrario, si las unidades predominantes son las acetiladas el producto sigue siendo quitina $[13,16]$.

Los grupos funcionales del quitosano corresponden a los enlaces $\mathrm{C}_{3}-\mathrm{OH}, \mathrm{C}_{6}-\mathrm{OH}$ y $\mathrm{C}_{2}-\mathrm{NH}_{2}$ [17]. Estos grupos le permiten interactuar con otras moléculas en solución y mostrar una serie de características únicas, tales como no toxicidad, biocompatibilidad, biodegradabilidad, actividades antibacterianas, antifúngicas, antiinflamatorias y antitumorales, así como capacidad de formación de películas, quelante, antioxidante y de unión a grasas [18, 19]. Cada unidad desacetilada contiene un grupo amino libre que cuando asume una carga positiva es el responsable no solo de otorgar la propiedad antimicrobiana al quitosano sino también quelante, siendo capaz de unirse a iones metálicos y absorber los aniones por atracción electrostática [8]. Gracias a todas estas características, el quitosano se considera un polímero multifuncional aplicable a una gran cantidad de industrias tales como la industria alimentaria, farmacéutica, biotecnológica, textil y del papel. Es ampliamente utilizado como antibacteriano y antifúngico y también se emplea en la agricultura y aplicaciones médicas. Del mismo modo, es beneficioso para el medio ambiente puesto que purifica aguas residuales y recupera el $\mathrm{CO}_{2}$ emitido por las industrias $[8,20]$. Sin embargo, este biopolímero también tiene limitaciones, pues es susceptible a factores ambientales como la temperatura y la humedad, los cuales pueden causar estrés en la estructura y conducir a su degradación. Además, es insoluble en agua y en la mayoría de los solventes orgánicos, por lo que su baja solubilidad en medios acuosos y su sensibilidad ambiental hacen que esté limitado su uso en los campos de aplicación [17, 21]. Por ese motivo, frente a las limitaciones del polímero, se presentan los quito-oligosacáridos (COS), productos obtenidos a partir de la degradación de la quitina y el quitosano, una excelente alternativa, pues estos copolímeros pueden disolverse en agua y, del mismo modo, se caracterizan por ser buenos agentes antimicrobianos [7]. 


\section{$\operatorname{COS}$}

Los quito-oligosacáridos (COS), también llamados oligómeros de quitosano o quito-oligómeros, son co-oligómeros lineales que se pueden obtener a través de la degradación física, química, electroquímica y enzimática tanto de la quitina como del quitosano [7, 22].

Estos co-oligómeros también poseen diversas funciones biológicas ya que mantienen las propiedades del quitosano, incluyendo acciones antioxidantes, antimicrobianas, antitumorales, antiinflamatorias e inductoras de defensa inmune. Los COS se utilizan en gran cantidad de aplicaciones potenciales en industrias médicas, alimentarias y farmacéuticas por ser solubles en agua y tener capacidad de absorción, biocompatibilidad y no ser tóxicos [22]. Sin embargo, si por algo se caracterizan los COS es por ser buenos agentes antimicrobianos, puesto que pueden inhibir y/o reducir el crecimiento de gran variedad de microorganismos, destacando patógenos o alterantes de alimentos, plantas y de animales [22].

\section{COS como antimicrobianos frente a los microorganismos más importantes en la industria alimentaria}

La industria alimentaria puede albergar multitud de microorganismos patógenos y alterantes que si no son controlados pueden conllevar a que el consumidor sufra una toxiinfección alimentaria. Las toxiinfecciones de este tipo se deben a la presencia de microorganismos o sus toxinas en los alimentos y es una problemática social que afecta tanto al consumidor como a la industria que ha elaborado el respectivo alimento. Con la finalidad de poder garantizar la seguridad alimentaria y evitar este tipo de problemas en la salud pública, se controla de forma estricta la presencia de cualquier microorganismo patógeno en los alimentos [20].

Los antimicrobianos se utilizan, junto con otros tratamientos, en la industria alimentaria para asegurar que la carga microbiológica presente en el alimento sea la permitida por la legislación cuando llegue al consumidor. Un ejemplo de ello es el uso de quito-oligosacáridos como antimicrobianos [20].

Dado que la Unión Europea apuesta por implantar una economía circular, los subproductos de la industria pesquera en los últimos años están aumentando de manera exponencial y las propiedades de los oligómeros de quitosano resultan prometedoras, el objetivo principal de este trabajo es analizar la capacidad biocida de diferentes formulaciones desarrolladas a partir de COS extraídos de subproductos de la industria pesquera, frente a los principales microorganismos alimentarios para, de este modo, revalorizarlos como antimicrobianos naturales presentes en formulaciones biocidas respetuosas con el medio ambiente.

\section{MATERIALES Y MÉTODOS}

En el estudio partimos de 7 muestras distintas de COS, todas ellas en estado sólido, en forma de polvo o escamas, correspondientes a $\operatorname{COS} 1, \operatorname{COS} 2, \operatorname{COS} 3, \operatorname{COS} 4, \operatorname{COS} 5, \operatorname{COS} 6$ y COS7. 
Los quito-oligómeros con distinto peso molecular y grado de desacetilación se obtuvieron a partir del quitosano extraído de exoesqueletos pertenecientes a distintas especies de crustáceos. Concretamente, se emplearon caparazones de gambas (Parapenaeus longirostris) y una mezcla de caparazones de centollo (Maja squinado) y buey (Cancer pagurus), como se observa en la tabla 1.

Tabla 1. Características de los COS utilizados

\begin{tabular}{ccccc}
\hline MUESTRA & COS & $\begin{array}{c}\text { GRADO DE } \\
\text { DESACETILACIÓN }\end{array}$ & $\begin{array}{c}\text { PESO } \\
\text { MOLECULAR }\end{array}$ & ORIGEN \\
\hline 1 & COS1 & $79 \%$ & $56 \mathrm{kDa}$ & Caparazones de gambas \\
2 & COS2 & $91,90 \%$ & $14 \mathrm{kDa}$ & Caparazones de gambas \\
3 & COS3 & $91,90 \%$ & $14 \mathrm{kDa}$ & Caparazones de gambas \\
4 & COS 4 & $94,70 \%$ & $4 \mathrm{kDa}$ & Caparazones de centollo y buey \\
5 & COS5 & $56 \%$ & $56 \mathrm{kDa}$ & Caparazones de gambas \\
6 & COS6 & $57-70 \%$ & $9 \mathrm{kDa}$ & Caparazones de gambas \\
7 & COS7 & $90 \%$ & $56 \mathrm{kDa}$ & Caparazones de gambas \\
\hline
\end{tabular}

COS: Quito-oligosacárido.

\section{Esterilización}

Durante la realización de todo el proyecto experimental, se realizaba la esterilización del material tanto antes de su uso como después de ser utilizado. En primer lugar, el material que iba a ser utilizado se preparaba correctamente utilizando doble capa de papel de aluminio y cinta de control de esterilización antes de introducirlo en el autoclave. Si, por el contrario, lo que se quería era esterilizar material ya utilizado, se introducía en bolsas de esterilización para evitar cualquier contaminación por microorganismos.

\section{Preparación de los COS}

En primer lugar, se pesó $1 \mathrm{~g}$ de cada COS y después se enrasó hasta $100 \mathrm{~mL}$ de agua destilada. Luego, mientras el pH-metro medía el pH de la solución en agitación continua, se iba añadiendo ácido clorhídrico lentamente, a gotas, hasta que el $\mathrm{pH}$ de la solución disminuía a 2. Llegados a este punto, se dejaba la muestra en agitación a 400 rpm durante dos horas. Pasado este tiempo, se añadía lentamente, hidróxido de sodio hasta que el pH alcanzaba un valor de 5 y se dejaba la muestra en agitación 1 hora aproximadamente. Finalmente, los vasos de precipitados con los COS diluidos se cubrían con parafilm y se conservaban en el frigorífico a $14{ }^{\circ} \mathrm{C}$ hasta su uso. 


\section{Formulación}

Se incluyeron los COS disueltos en agua en formulaciones con potencial capacidad biocida. Para ello, se añadieron en las diferentes formulaciones, además de los COS, diferentes materias primas con distintas capacidades, con el objetivo de mejorar su capacidad biocida. De ese modo, se desarrollaron diferentes formulaciones para cada uno de los COS y se sometieron a un estudio de estabilidad consistente en la evaluación de la aparición de turbidez, precipitado o separación de fases durante 72 horas a diferentes temperaturas $\left(4{ }^{\circ} \mathrm{C}\right.$, temperatura ambiente y $\left.45^{\circ} \mathrm{C}\right)$, en presencia/ausencia de luz. Los resultados del estudio de estabilidad nos permitieron seleccionar el formulado más estable para cada COS. La estabilidad de los formulados era una variable muy importante puesto que dichos formulados, junto a los respectivos COS, eran el objeto de estudio de este trabajo.

\section{Preparación del stock de microorganismos}

A partir de liófilos obtenidos de la Colección Española de Cultivos Tipo (CECT), se obtuvieron stocks de los siguientes microorganismos: Pseudomonas aeruginosa, Staphylococcus aureus, Escherichia coli, Listeria monocytogenes, Salmonella enterica y Candida albicans. Para ello, se hizo crecer cada uno de los microorganismos utilizados en un caldo de cultivo óptimo y a continuación se separaron las células microbianas por centrifugación, dando lugar a un stock de cada microorganismo que se conservó en congelación en un medio crioprotector hasta su uso [23].

\section{Crecimiento de microorganismos y evaluación de la capacidad biocida}

Un criovial del stock de cada uno de los microorganismos estudiados fue inoculado en $50 \mathrm{~mL}$ de caldo de cultivo óptimo (TSB en el caso de bacterias y BHI en el caso de hongos) y se incubaron a $37^{\circ} \mathrm{C}$ durante $15-20$ horas para obtener una concentración microbiana de $10^{7}-10^{8} \mathrm{ufc} / \mathrm{mL}$.

Para evaluar la capacidad biocida en suspensión de cada formulado frente a los diferentes microorganismos, se siguió la norma UNE-EN 1276. De esta manera, los ensayos se realizaron en las condiciones más adversas posibles, es decir, en condiciones sucias, mediante el uso de albúmina bovina ( $3 \mathrm{~g} / \mathrm{L})$ como sustancia interferente y agua dura para la disolución de los diferentes formulados.

\section{Recuento en placa y análisis de resultados}

Tras la exposición de los microorganismos a cada uno de los formulados, se procedió a la siembra en placa por dilución seriada y la posterior incubación a $37{ }^{\circ} \mathrm{C}$ durante 24 horas para su recuento. Asimismo, se incluyeron como controles ensayos con cada uno de los microrganismos en los que se sustituyó la exposición a cada uno de los formulados por agua dura.

La variable objeto de estudio correspondía al recuento en placa de microorganismos tras la aplicación de los diferentes formulados con respecto al recuento en placa de las muestras control para cada 
microorganismo. Los datos obtenidos se analizaron utilizando el programa Microsoft Excel (Office 365), para el cálculo de promedios, desviaciones típicas, logaritmos e inactivaciones, así como la realización de gráficas.

A partir de los recuentos obtenidos en cada caso, se calculaba su promedio y desviación típica, así como su logaritmo decimal. Finalmente, se calculaban los ciclos logarítmicos de inactivación por diferencia entre los ciclos logarítmicos de recuento obtenidos en cada combinación formulado-microorganismo y los ciclos logarítmicos obtenidos de recuento en la muestra control con agua dura estéril en cada caso. En cada gráfico se representan las barras de error obtenidas mediante el análisis estadístico de los recuentos obtenidos.

\section{RESULTADOS Y DISCUSIÓN}

\section{Evaluación de la estabilidad de los formulados}

Se partió de 7 COS distintos correspondientes a COS1, COS2, COS3, COS4, COS5, COS6 y COS7.

Tras evaluar las distintas formulaciones desarrolladas para cada COS, se eligieron aquellas que mejor estabilidad evidenciaban en cada caso. De ese modo, COS5 quedó descartado en este paso puesto que mostró ser no viable debido a su elevada viscosidad al entrar en contacto con los tensioactivos de los formulados, lo que hacía imposible su disolución. Este hecho coincide con la evidencia científica publicada en la bibliografía estudiada, en la que se informa de que un menor grado de desacetilación está asociado con una menor solubilidad $[9,20]$. En el estudio, COS5 es el quito-oligosacárido que presenta un menor grado de desacetilación (56\%), por lo que cabía esperar que fuese el COS menos soluble.

\section{Estudio de las condiciones óptimas para evaluar la capacidad biocida de los formulados}

Se determinó 5 minutos como tiempo de exposición y diluir los formulados al $10 \%$ para obtener niveles de inactivación que permitieran comparar el efecto biocida de los diferentes formulados, además de inactivar los 5 ciclos logarítmicos establecidos por la norma UNE-EN 1276 para el registro de productos biocidas en suspensión. Asimismo, se descartó la adición de hidróxido de sodio, utilizado para neutralizar el pH de la disolución de los COS, ya que este protonaba los grupos amino de los COS disminuyendo su capacidad biocida [17, 19]. Cabe mencionar que el pH de la formulación final, como se muestra en la tabla 2, no se veía afectado al no añadir $\mathrm{NaOH}$ a los quito-oligosacáridos disueltos, puesto que la cantidad de COS en los formulados es tan solo de un $1 \%$. 
Tabla 2. pH de los formulados

\begin{tabular}{lcc}
\hline & $\mathrm{pH}$ con NaOH & $\mathrm{pH} \operatorname{sin~NaOH}$ \\
\hline Formulado 1 & 10,50 & 10,54 \\
Formulado 2 & 10,50 & 10,43 \\
Formulado 3 & 10,50 & 10,62 \\
Formulado 4 & 11,80 & 11,86 \\
Formulado 6 & 11,60 & 11,77 \\
Formulado 7 & 10,30 & 10,64 \\
\hline
\end{tabular}

Además, como se observa en la tabla 3 , los valores de $\mathrm{pH}$ de los formulados diluidos al $10 \%$ con agua dura se encuentran más cercanos a la neutralidad y nos permiten poder estudiar la capacidad biocida de los formulados desarrollados, lo que evita un posible efecto biocida debido al $\mathrm{pH}$.

Tabla 3. pH de los formulados

\begin{tabular}{lc}
\hline & $\mathrm{pH}$ formulados diluídos al $10 \%$ con agua dura \\
\hline Formulado 1 & 9,36 \\
Formulado 2 & 9,42 \\
Formulado 3 & 9,46 \\
Formulado 4 & 9,56 \\
Formulado 6 & 9,60 \\
Formulado 7 & 9,28 \\
\hline
\end{tabular}

\section{Capacidad biocida de los formulados frente a los principales microorganismos de la industria alimentaria}

\section{Bacterias Gram-negativas}

En la figura 1 se representa la inactivación de las bacterias Gram-negativas en estudio al ser expuestas durante 5 minutos a los diferentes formulados. 



Fig. 1. Inactivación celular de A) P. aeruginosa; B) E. coli; y C) S. enterica en escala logarítmica causada por los diferentes formulados diluidos al $10 \%$ y a los 5 minutos de exposición. Fuente: elaboración propia.

Podemos observar en la figura 1A que en $P$. aeruginosa el valor de inactivación más elevado corresponde a COS1, con 4,31 ciclos logarítmicos de inactivación. 
En cambio, en el caso de $E$. coli (figura 1B) es el formulado COS7 el que alcanza un mayor grado de inactivación (4,27 ciclos logarítmicos).

En cuanto a $S$. enterica que se muestra en la figura $1 \mathrm{C}$, el mayor valor de inactivación se ha obtenido en el formulado COS3, el cual ha sido capaz de inhibir 6,55 ciclos logarítmicos del microorganismo. Además, $S$. enterica fue el microorganismo de los estudiados más sensible al efecto biocida de los formulados. Este tipo de resultados han sido observados también por otros autores, ya que la actividad antibacteriana de los COS también depende del tipo de bacteria a la que se enfrenten, según se demuestra en la literatura científica [15].

Los resultados obtenidos demuestran que en bacterias Gram-negativas a mayor peso molecular, grado de desacetilación o una combinación de ambos, mayor actividad bactericida muestran los COS $[15,20,24]$.

En cambio, los formulados basados en moléculas de COS con un peso molecular menor, como es el caso de COS4 y COS6 presentan una débil inactivación en las 3 bacterias [25].

\section{Bacterias Gram-positivas}

La inactivación de las bacterias Gram-positivas estudiadas se observa en la siguiente figura:

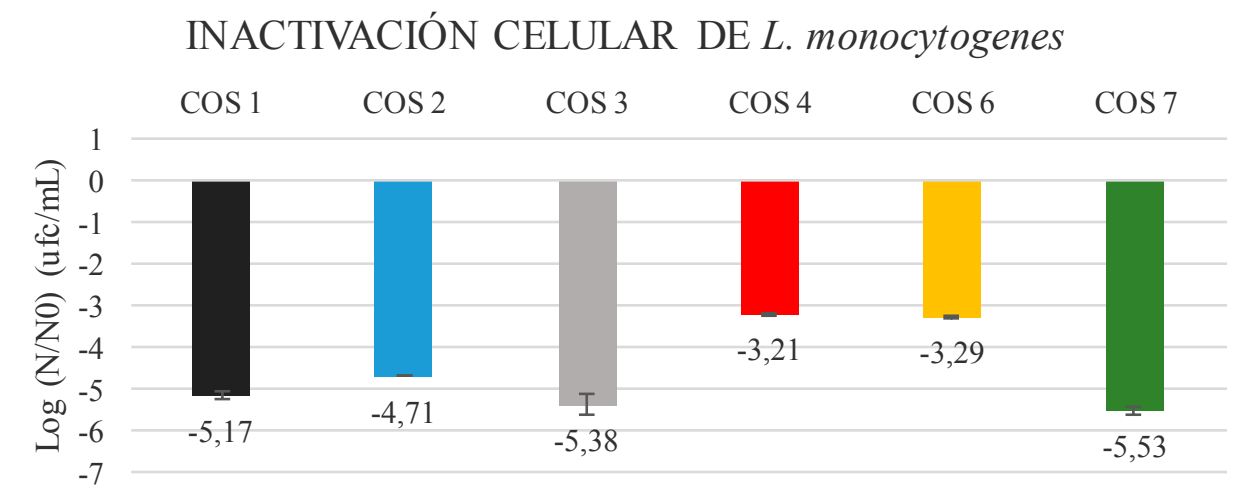

INACTIVACIÓN CELULAR DE S. aureus

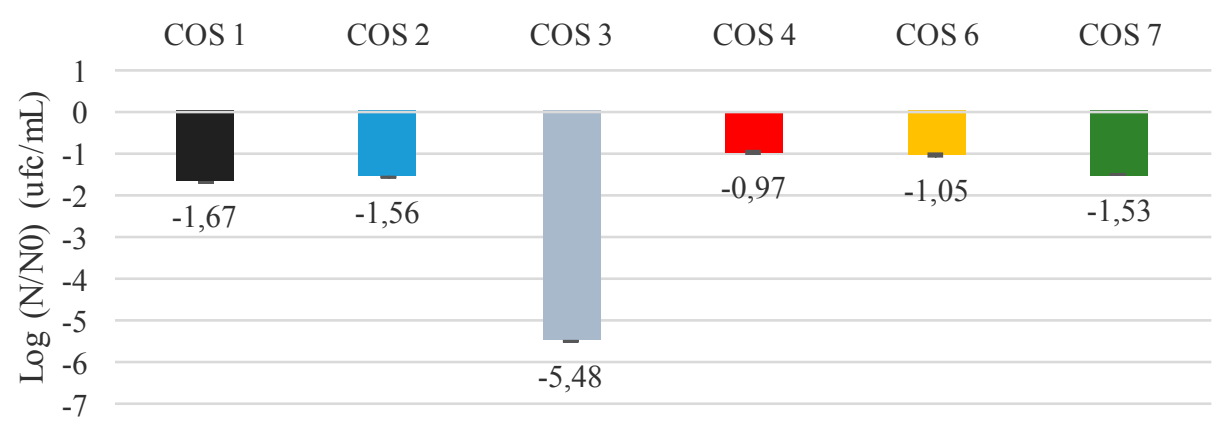

Fig. 2. Inactivación celular de A) L. monocytogenes y B) S. aureus en escala logarítmica causada por los diferentes formulados diluidos un $10 \%$ y a los 5 minutos de exposición. Fuente: elaboración propia. 
En la figura 2A, se muestra el efecto biocida de los formulados frente a L. monocytogenes. En este caso, hay 3 formulados que inactivan más de 5 ciclos logarítmicos COS1, COS3 y COS7, al igual que en el estudio [26], en el cual diferentes COS también son capaces de inhibir 5 ciclos logarítmicos de L. monocytogenes.

En el caso de $S$. aureus, se distingue claramente que el formulado con mayor valor de inactivación es COS3, el cual inhibe 5,48 ciclos logarítmicos. Este formulado posee uno de los grados de desacetilación más elevados $(91,90 \%$ ) y un peso molecular de $14 \mathrm{kDa}$. Estos resultados coinciden con los encontrados en algunos estudios científicos como el realizado por Ayala [20], un artículo de revisión en el cual se estudia el efecto antimicrobiano del quitosano, en el que se reporta que se alcanza una mayor inhibición en $S$. aureus cuanto mayor es el grado de desacetilación.

Respecto a los formulados COS4 y COS6 inhiben más de 3 ciclos logarítmicos en L. monocytogenes siendo su mejor resultado en todo el estudio. Este hecho puede deberse, como se menciona en el estudio publicado por Aranaz [15], a que las bacterias Gram-positivas parecen ser más sensibles que las Gram-negativas a los quito-oligosacáridos.

\section{Hongos}

Asimismo, estudiamos la actividad antifúngica de los formulados desarrollados frente a C. albicans, la cual se puede observar en la figura 3.

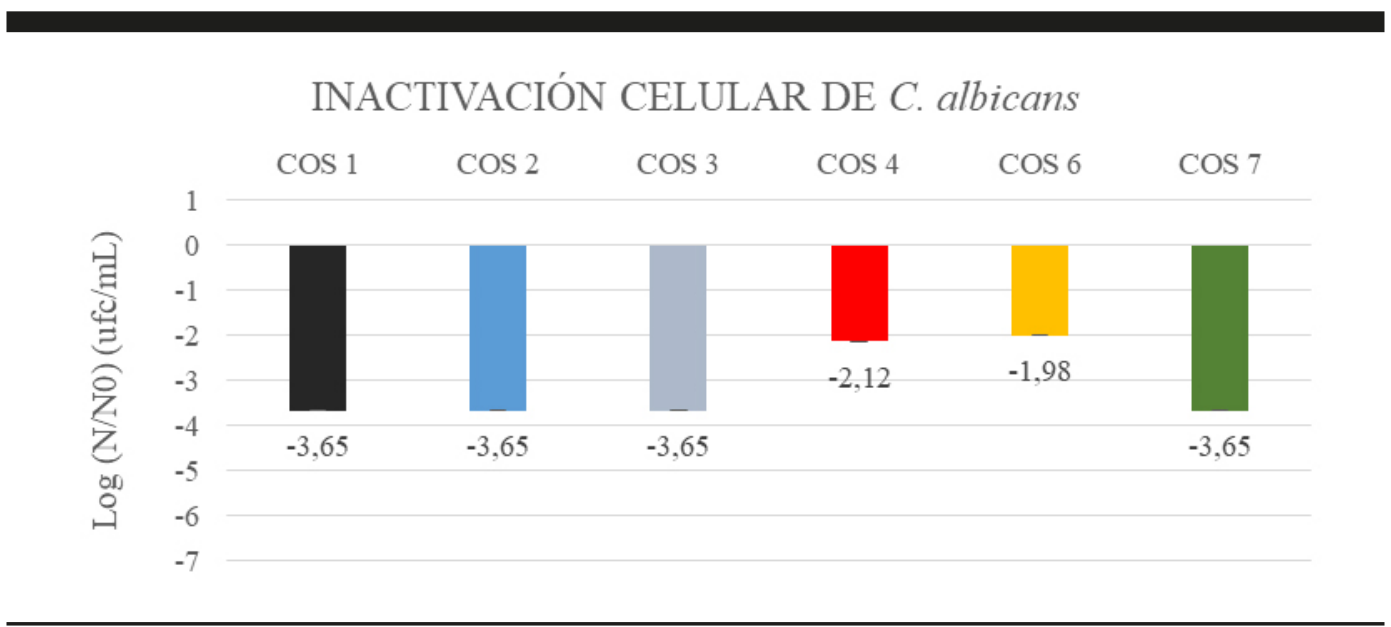

Fig. 3. Inactivación celular de C. albicans en escala logarítmica causada por los diferentes formulados diluidos al $10 \%$ y a los 5 minutos de exposición. Fuente: elaboración propia.

Se ha demostrado en los estudios científicos publicados hasta la fecha que los COS presentan actividad antifúngica en algunos hongos como $C$. albicans [24]. En este caso, como se observa en la figura 3, los formulados $\operatorname{COS} 1, \operatorname{COS} 2, \operatorname{COS} 3$ y COS7 inhiben 3,5 ciclos logarítmicos, siendo estos COS los que presentan un mayor peso molecular. Estos resultados están en concordancia con los obtenidos en otras publicaciones científicas como [24], donde se estudia tanto las actividades biológicas como las aplicaciones terapéuticas de los quito-oligosacáridos y en el que se demuestra que la actividad antifúngica aumenta al aumentar el peso molecular y el grado de desacetilación. 
En cambio, los formulados COS4 y COS6 inhiben 2 ciclos logarítmicos, corroborando lo mencionado en la bibliografía. Sin embargo, existen estudios científicos, como los recopilados en la revisión [13], donde se estudian los oligómeros de quitosano y sus actividades biológicas, en los que se muestra que la actividad antifúngica es mayor cuanto menor es el peso molecular, y eso explicaría los 2 ciclos logarítmicos inhibidos por COS4 y COS6.

Por último, cabe mencionar que los resultados pueden ser contradictorios comparados con los de otros autores, dependiendo de la fuente a la que pertenezcan los COS, los métodos de preparación, los microorganismos objetivo y las condiciones a las que se lleva a cabo el experimento, puesto que todos estos factores pueden dar como resultado diferentes subproductos así como una estructura química de los COS distinta por diferenciación en la posición de los grupos terminales [22].

De cara a futuras investigaciones científicas en este ámbito, se requiere seguir investigando el formulado basado en el COS3, ya que es necesario que este cumpla con las normas establecidas para los productos biocidas, así como estudiar cualquier método que permita potenciar aún más su actividad antimicrobiana, como la mejora de las formulaciones, para desarrollar un producto biocida de carácter sostenible. Asimismo, una vez obtenida la fórmula definitiva, se procederá a realizar estudios de semiescalado industrial, para, de este modo, evaluar si la capacidad biocida observada a escala del laboratorio se mantiene al escalar a nivel semiindustrial tanto el proceso de obtención de los COS a partir de subproductos de la industria pesquera, como su posterior dilución en agua y su inclusión como parte de formulaciones sostenibles novedosas. De esta manera, se contribuirá a la revalorización de los COS extraídos de subproductos de la industria pesquera como antimicrobianos naturales en formulaciones biocidas respetuosas con el medio ambiente, siguiendo, además, con los objetivos del modelo de economía circular que la Unión Europea desea implantar.

\section{CONCLUSIÓN}

Los resultados obtenidos a lo largo del presente trabajo han permitido concluir que los quitooligosacáridos con un grado de desacetilación por debajo del $57 \%$ poseen una solubilidad baja, y la neutralización de $\mathrm{pH}$ mediante la adición de hidróxido de sodio tras la disolución de los quitooligosacáridos influye en la actividad antimicrobiana de estos disminuyéndola. Además, se ha comprobado que, a mayor tiempo de exposición, concentración de quito-oligosacáridos, peso molecular y grado de desacetilación, mayor actividad antimicrobiana presentan los COS. En este caso, S. enterica y L. monocytogenes son los microorganismos estudiados que mayor sensibilidad presentan frente al efecto biocida de los formulados desarrollados siendo, en general, las bacterias Gram-positivas más sensibles a la actividad antimicrobiana de quito-oligosacáridos de bajo peso molecular que las Gram-negativas.

En cuanto a los formulados, el basado en el COS3 es el que presenta una mayor capacidad biocida tanto frente a bacterias como frente al hongo estudiado. Por ello, es el candidato que mayor proyección presenta para el desarrollo de un futuro producto biocida sostenible que contribuya a la implantación de un sistema de economía circular. 


\section{AGRADECIMIENTOS}

Los autores desean agradecer tanto a BETELGEUX-CHRISTEYNS y a todo su personal por el apoyo recibido y haber permitido realizar este trabajo, como al Centro para el Desarrollo Tecnológico Industrial (CDTI) y al Ministerio de Ciencia e Innovación por la financiación del proyecto BIOCOS de la convocatoria EUREKA, en el cual se engloba el presente trabajo.

\section{REFERENCIAS BIBLIOGRÁFICAS}

[1] Macarthur E. Economía Circular. Ellen Macarthur Foundation; 2017. Disponible en: https:// www.ellenmacarthurfoundation.org/es/economia-circular/concepto.

[2] Rekondo J. De la economía lineal, a la circular: un cambio necesario; 2019. Disponible en: https://www.ategrus.org/noticias/de-la-economia-lineal-a-la-circular-un-cambio-necesario/.

[3] CE. La UE apuesta fuerte por la economía circular; 2020. Disponible en: https://ec.europa.eu/ spain/news/20190218_\%20The-EU-is-strongly-committed-to-circular-economy_es.

[4] Ravindran R, Jaiswal AK. Exploitation of Food Industry Waste for High-Value Products. Trends in biotechnology. 2016;34(1):58-69.

[5] Gomez-Brandon M, Lores M, Insam H, Dominguez J. Strategies for recycling and valorization of grape marc. Critical reviews in biotechnology. 2019;39(4):437-50.

[6] Lopes C, Antelo LT, Franco-Uria A, Alonso AA, Perez-Martin R. Valorisation of fish by-products against waste management treatments--Comparison of environmental impacts. Waste management. 2015;46:103-12.

[7] Kaczmarek MB, Struszczyk-Swita K, Li X, Szczesna-Antczak M, Daroch M. Enzymatic Modifications of Chitin, Chitosan, and Chitooligosaccharides. Frontiers in bioengineering and biotechnology. 2019;7:243.

[8] El Knidri H, Belaabed R, Addaou A, Laajeb A, Lahsini A. Extraction, chemical modification and characterization of chitin and chitosan. International journal of biological macromolecules. 2018;120(Pt A):1181-9.

[9] Kumari S, Kumar Annamareddy SH, Abanti S, Kumar Rath P. Physicochemical properties and characterization of chitosan synthesized from fish scales, crab and shrimp shells. International journal of biological macromolecules. 2017;104(Pt B):1697-705.

[10] Grifoll-Romero L, Pascual S, Aragunde H, Biarnes X, Planas A. Chitin Deacetylases: Structures, Specificities, and Biotech Applications. Polymers. 2018;10(4).

[11] Azuma K, Izumi R, Osaki T, Ifuku S, Morimoto M, Saimoto H, et al. Chitin, chitosan, and its derivatives for wound healing: old and new materials. Journal of functional biomaterials. 2015;6(1):104-42.

[12] Halder SK, Mondal KC. Microbial Valorization of Chitinous Bioresources for Chitin Extraction and Production of Chito-Oligomers and N-Acetylglucosamine: Trends, Perspectives and Prospects. 2018;10.1007/978-981-10-7140-9_4:69-107.

[13] Liaqat F, Eltem R. Chitooligosaccharides and their biological activities: A comprehensive review. Carbohydrate polymers. 2018;184:243-59. 
[14] Martau GA, Mihai M, Vodnar DC. The Use of Chitosan, Alginate, and Pectin in the Biomedical and Food Sector-Biocompatibility, Bioadhesiveness, and Biodegradability. Polymers. 2019;11(11).

[15] Aranaz I, Acosta N, Civera C, Elorza B, Mingo J, Castro C, et al. Cosmetics and Cosmeceutical Applications of Chitin, Chitosan and Their Derivatives. Polymers. 2018;10(2).

[16] Naqvi S, Moerschbacher BM. The cell factory approach toward biotechnological production of high-value chitosan oligomers and their derivatives: an update. Critical reviews in biotechnology. 2017;37(1):11-25.

[17] Wang, Meng, Li Q, Liu J, Zhou M, Jin Z, et al. Chitosan Derivatives and Their Application in Biomedicine. International journal of molecular sciences. 2020;21(2).

[18] Palou L, Ali A, Fallik E, Romanazzi G. GRAS, plant- and animal-derived compounds as alternatives to conventional fungicides for the control of postharvest diseases of fresh horticultural produce. Postharvest Biology and Technology. 2016;122:41-52.

[19] Schmitz C, Auza LG, Koberidze D, Rasche S, Fischer R, Bortesi L. Conversion of Chitin to Defined Chitosan Oligomers: Current Status and Future Prospects. Marine drugs. 2019;17(8).

[20] Ayala G. Efecto antimicrobiano del quitosano. Scientia Agroalimentaria 2015;2:32-8.

[21] Wei L, Li Q, Chen Y, Zhang J, Mi Y, Dong F, et al. Enhanced antioxidant and antifungal activity of chitosan derivatives bearing 6-O-imidazole-based quaternary ammonium salts. Carbohydrate polymers. 2019;206:493-503.

[22] Liang, Sun, Dai. A review of the preparation, analysis and biological functions of chitooligosaccharide. International journal of molecular sciences. 2018;19(8):2197.

[23] Sanz-Puig M, Pina-Pérez MC, Criado MN, Rodrigo D, Martínez-López A. Antimicrobial potential of cauliflower, broccoli, and okara byproducts against foodborne bacteria. Foodborne pathogens and disease. 2015;12(1):39-46.

[24] Muanprasat C, Chatsudthipong V. Chitosan oligosaccharide: Biological activities and potential therapeutic applications. Pharmacology \& therapeutics. 2017;170:80-97.

[25] Varun TK, Senani S, Jayapal N, Chikkerur J, Roy S, Tekulapally VB, et al. Extraction of chitosan and its oligomers from shrimp shell waste, their characterization and antimicrobial effect. Veterinary world. 2017;10(2):170-5.

[26] Jovanovic GD, Klaus AS, Niksic MP. Antimicrobial activity of chitosan coatings and films against Listeria monocytogenes on black radish. Revista Argentina de microbiologia. 2016;48(2):128-36. 